\title{
Suppression of Ventricular Arrhythmias in Man by d-Propranolol Independent of Beta-Adrenergic Receptor Blockade
}

\author{
Katherine T. Murray, Charles Reilly, Richard P. Koshakji, ${ }^{\dagger}$ Dan M. Roden, Mark D. Lineberry, \\ Alastair J. J. Wood, Lyle A. Siddoway, Jean T. Barbey, and Raymond L. Woosley \\ Departments of Medicine and Pharmacology, Vanderbilt University School of Medicine, Nashville, Tennessee 37232
}

\begin{abstract}
To investigate the mechanisms of ventricular arrhythmia suppression by propranolol, we determined the antiarrhythmic efficacy of $d$-propranolol in 10 patients with frequent ventricular ectopic depolarizations (VEDs) and nonsustained ventricular tachycardia. After an initial placebo phase, $40 \mathrm{mg} d$-propranolol was administered orally every $6 \mathrm{~h}$ with dosage increased every 2 d until arrhythmia suppression ( $\geq 80 \%$ VED reduction), intolerable side effects, or a maximal dosage $(1,280$ $\mathrm{mg} / \mathrm{d}$ ) was reached. Response was verified by documenting return of arrhythmia during a final placebo phase. Arrhythmia suppression occurred in six patients while two more had partial responses. Effective dosages were $320-1,280 \mathrm{mg} / \mathrm{d}$ (mean $920 \pm 360, \mathrm{SD})$ of $d$-propranolol with corresponding plasma concentrations of $60-2,280 \mathrm{ng} / \mathrm{ml}$ (mean $858 \pm 681$ ). For the entire group, the QTc interval shortened by $4 \pm 4 \%(P=0.03)$. Arrhythmia suppression was accompanied by a reduction in peak heart rate during exercise of 0-29\%. To determine whether arrhythmia suppression could be attributed to betablockade, racemic propranolol was then administered in dosages producing the same or greater depression of exercise heart rate. In $3 / 8$ patients, arrhythmias were not suppressed by racemic propranolol indicating that $d$-propranolol was effective via a non-beta-mediated action. By contrast, in 5/8 patients racemic propranolol also suppressed VEDs. We conclude that propranolol suppresses ventricular arrhythmias by both beta- and non-beta-adrenergic receptor-mediated effects. (J. Clin. Invest. 1990. 85:836-842.) propranolol • antiarrhythmic • ventricular arrhythmias - dextropropranolol • betaadrenergic receptor blockade
\end{abstract}

\section{Introduction}

Although propranolol has been used clinically in the United States for over 20 years, its mechanism(s) of action are not fully understood. Recently in the Beta-blocker Heart Attack Trial (BHAT), propranolol was found to reduce mortality after acute myocardial infarction (1). Since other beta receptor an-

${ }^{\dagger}$ Deceased

Presented in abstract form at the 57th Annual Scientific Sessions of the American Heart Association, in 1984.

Address reprint requests to Dr. Murray, Division of Clinical Pharmacology, Vanderbilt University School of Medicine, 560 Medical Research Building, Nashville, TN 37232-6602.

Received for publication 29 November 1988 and in revised form 22 September 1989.

J. Clin. Invest.

(C) The American Society for Clinical Investigation, Inc.

0021-9738/90/03/0836/07 \$2.00

Volume 85, March 1990, 836-842 tagonists have demonstrated similar results with reduction in both nonsudden cardiovascular mortality and reinfarction rate (2-4), the antiischemic effects of beta-adrenergic receptor blockade almost certainly played a role in this beneficial effect. However, a significant reduction in the incidence of sudden cardiac death was also observed during BHAT, raising the question of an additional antiarrhythmic effect. Subsequent data analysis from the trial supported this hypothesis, as propranolol blunted the usual increase in ventricular ectopic depolarizations (VEDs) ${ }^{1}$ seen 6 wk after enrollment (5) and reduced mortality to the greatest extent in patients with mechanical and electrical complications such as ventricular tachycardia or fibrillation (6).

In addition to its beta-adrenergic receptor antagonism, propranolol also possesses "local anesthetic" activity in that it reduces sodium channel conductance. In an early report, this effect could be demonstrated in vitro at only very high concentrations of propranolol that are not routinely achieved during clinical use (7). Because of these data as well as the fact that propranolol is generally less effective than standard antiarrhythmic agents such as quinidine in suppressing ventricular arrhythmias (8-10), many investigators have attributed its antiarrhythmic effects to beta-adrenergic receptor blockade (11, 12 ). In a more recent study (13) using a wide range of propranolol dosages to treat frequent VEDs, $40 \%$ of the patients with arrhythmia suppression required plasma propranolol concentrations $>150 \mathrm{ng} / \mathrm{ml}$, a level associated with a high degree of beta blockade $(14,15)$. These results raised the possibility that some property other than beta-adrenergic receptor blockade was responsible for ventricular arrhythmia suppression in some patients. It now appears that propranolol produces local anesthetic effects in vitro at much lower concentrations than previously reported (16-18). Moreover, we have demonstrated electrophysiologic effects in man using intracardiac recordings during propranolol administration that are unrelated to beta-adrenergic receptor blockade $(19,20)$. The contribution of these non-beta-mediated effects to the antiarrhythmic efficacy of propranolol has remained unclear.

Commercial propranolol is a racemic mixture of dextroand levo-rotatory stereoisomers (21) with the $l$-isomer far more potent in producing beta-adrenergic receptor antagonism than the $d$-isomer (22). However, the two stereoisomers are equipotent as local anesthetics $(18,23)$. The purpose of this study was to examine the antiarrhythmic efficacy of $d$-propranolol in patients with chronic, stable ventricular arrhythmias. When antiarrhythmic efficacy was demonstrated, we sought also to determine the contribution of non-beta-receptor mediated actions to the antiarrhythmic effect.

1. Abbreviations used in this paper: $\mathrm{APD}$, action potential duration; AUC, area under the curve; $\mathrm{CD}_{25}$, chronotropic dose ${ }_{25}$, IDR, isoproterenol dose ratio; $\mathrm{K}_{\mathrm{el}}$, elimination half-life; VED, ventricular ectopic depolarization; VERP, ventricular effective refractory period. 


\section{Methods}

Patient selection. Adult patients were eligible for participation in the study if they demonstrated symptomatic chronic, frequent VEDs $(>60 / \mathrm{h}$ ) and nonsustained ventricular tachycardia ( $\leq 15$ beats) at baseline in the absence of any antiarrhythmic drug therapy. Patients were excluded who had a recent myocardial infarction, symptoms of angina and/or congestive heart failure indicating New York Heart Association functional Class III or IV, clinically significant or sustained supraventricular tachyarrhythmias, or evidence of significant conduction system disease (sinus node dysfunction, Mobitz II second degree or greater AV block, left bundle branch block, prolonged QT interval). Patients in whom beta-adrenergic receptor blockade was contraindicated (history of bronchospasm or chronic pulmonary disease requiring bronchodilator therapy) were also excluded (2).

Study design. Informed consent was obtained and all antiarrhythmic agents were discontinued for at least four elimination half-lives before enrollment. Patients were admitted to the Clinical Research Center at Vanderbilt University Hospital where they were continuously monitored via telemetric ECG throughout the study. A questionnaire was administered daily to detect the occurrence of adverse effects. The arrhythmia suppression trial was conducted in a singleblind fashion. During the initial placebo phase (one placebo taken orally every $6 \mathrm{~h}$ ), 24-h ambulatory electrocardiographic recordings were obtained for at least $48 \mathrm{~h}$ as well as a 12-lead electrocardiogram and a blood sample to demonstrate that propranolol was not detectable. Data from the entire placebo period were averaged to obtain baseline VED frequency. Patients also underwent exercise testing using the Bruce protocol (24).

After baseline data were obtained, patients were given $d$-propranolol $40 \mathrm{mg}$ orally ever $6 \mathrm{~h}$. On the second day of dosing, a 12-lead electrocardiogram and blood sample for plasma propranolol concentration were obtained before the morning dose and 24-h ambulatory electrocardiographic recording was repeated. The dosage of $d$-propranolol was increased every $2 \mathrm{~d}$ until the occurrence of either arrhythmia suppression, adverse effects limiting dose escalation, or a maximal dosage of $320 \mathrm{mg}$ orally every $6 \mathrm{~h}$. Effective arrhythmia suppression was defined as $\geq 80 \%$ VED suppression with elimination of nonsustained ventricular tachycardia. At the highest dosage of $d$-propranolol administered during the study, exercise testing was repeated. Patients then underwent a drug withdrawal phase lasting at least $72 \mathrm{~h}$ during which placebo was administered and multiple blood samples were obtained for pharmacokinetic analysis. If patients with arrhythmia suppression on $d$-propranolol also had a reduction in peak exercise heart rate during therapy, $d l$-propranolol was then administered in a dose that produced a similar or greater degree of reduction in exercise heart rate. The choice of $d l$-propranolol dosage to be administered was based on the degree of reduction in peak exercise heart rate observed with $d$-propranolol: for patients in whom the peak exercise heart rate decreased 5-15 bpm, $d$-propranolol $5 \mathrm{mg}$ orally every $6 \mathrm{~h}$ was given; for those with a 16-30-bpm reduction, $10 \mathrm{mg}$ orally every $6 \mathrm{~h}$ was administered; for those with a $>30$-bpm reduction, 20 mg orally every $6 \mathrm{~h}$ was given. Arrhythmia frequency was reassessed by 24-h ambulatory electrocardiographic monitoring. $d$-Propranolol tablets $(40 \mathrm{mg})$ and matching placebos were kindly supplied by Imperial Chemical Industries, Ltd., Macclesfield, UK.

Electrocardiographic analysis. 12-lead electrocardiograms were recorded at a paper speed of $25 \mathrm{~mm} / \mathrm{s}$ and intervals were recorded from a single limb lead. Interval measurement was performed using a digitizing board (Bit Pad I, Summagraphics) connected to a microcomputer. Ambulatory electrocardiographic recordings were analyzed by a userinteractive template-matching computer system previously validated at our institution (25).

Pharmacokinetic analysis. During the drug withdrawal phase of the study, blood samples were obtained for measurement of plasma propranolol concentration at $0,0.5,1,1.5,2,3,4,6,8,12,18,24,30,36$, 48,60 , and $72 \mathrm{~h}$ after the last oral dose of $d$-propranolol. Plasma propranolol concentrations were measured using a high performance liquid chromatographic assay with fluorescence detection previously described (26). Linear regression analysis was performed on the terminal phase of the semilogarithmic plot of plasma propranolol concentration vs. time. Elimination half-life was calculated as 0.693 divided by $K_{e l}$ where $K_{e l}$ equals the negative slope of the terminal phase. The area under the plasma concentration-time curve for the dosing interval 0-6 $\mathrm{h}\left(\mathrm{AUC}_{0-6}\right)$ was determined using the log trapezoidal rule method. Clearance was calculated by dividing the dose by $\mathrm{AUC}_{0-6}$.

Analysis of beta-adrenergic receptor blocking potency of d-propranolol. To examine the potency of $d$-propranolol with respect to that of racemic propranolol, we compared the degree of beta-blockade produced by the $d$-isomer with that produced by $d l$-propranolol in a separate group of normal adult volunteers. After obtaining informed consent, normal adult volunteers were brought to the Clinical Research Center in the fasting postabsorptive state for baseline assessment of sensitivity to isoproterenol. A heparin-filled intravenous catheter was inserted and continuous electrocardiographic monitoring was performed using a four-channel (model 1572; Hewlett-Packard Co., Palo Alto, CA) recorder with heart rate monitor. Isoproterenol sensitivity testing, as previously described (27), was performed to determine the dose required to raise the baseline heart rate by $25 \mathrm{bpm}$ (chronotropic dose $_{25}$ or $\mathrm{CD}_{25}$ ). Subjects were then given an oral dose of $d l$-propranolol $10 \mathrm{mg}$ every $6 \mathrm{~h}$ for $48 \mathrm{~h}$, with isoproterenol testing repeated $2 \mathrm{~h}$ after the subsequent morning dose. The isoproterenol dose ratio (IDR) was calculated by dividing the $\mathrm{CD}_{25}$ obtained during propranolol administration by the $\mathrm{CD}_{25}$ at baseline. Isoproterenol sensitivity testing was also repeated after treatment for $48 \mathrm{~h}$ with $\mathrm{dl}$-propranolol given orally every $6 \mathrm{~h}$ at both 20 - and 40-mg doses, and $d$-propranolol 320 $\mathrm{mg}$ orally every $6 \mathrm{~h}$. Values obtained from blood samples drawn before and after isoproterenol administration were averaged to give the plasma propranolol concentration at the time of testing.

Statistical analysis. Comparison of all data in patients at baseline and following $d$-propranolol administration (maximal dosage administered) were made using Student's paired $t$ test. A $P$ value $<0.05$ was required to reject the null hypothesis. Linear regression analyses were performed using standard least-squares fit. All results are expressed as mean $\pm 1 \mathrm{SD}$.

\section{Results}

Patient population. 10 male patients ages 35-71 (mean 53) y participated in the arrhythmia suppression trial. The characteristics of this population are shown in Table I. Mean VED frequency for the group averaged 599/h. During trials with previous antiarrhythmic agents, patients had been refractory to treatment with two to seven (mean 3.8) drugs, and four patients had failed to respond to therapy with beta-adrenergic receptor antagonists. 8 of the 10 patients were receiving investigational antiarrhythmic drugs at the time of enrollment. In all patients, VED frequency decreased with the sinus tachycardia that occurred during baseline exercise testing and as such, there was no obvious evidence of adrenergically mediated arrhythmias in any participant.

Ventricular arrhythmia suppression. The plasma propranolol concentration-response relationship for VED suppression for all patients is illustrated in Fig. 1. The $d$-propranolol dosage administered is shown for each trough plasma concentration. Arrhythmia suppression is expressed as percentage of baseline VED frequency. Six patients had an excellent response with $\geq 80 \%$ VED suppression and elimination of nonsustained VT during treatment with $d$-propranolol. This occurred at total daily dosages of $320 \mathrm{mg}$ (one patient), $640 \mathrm{mg}$ (two patients), $960 \mathrm{mg}$ (two patients), and 1,280 mg (one patient). Two additional patients had a partial response ( $\geq 50 \%$ VED reduction) having $73 \%$ and $66 \%$ VED suppression. Both patients required 
Table I. Patient Population

\begin{tabular}{|c|c|c|c|c|}
\hline Patient & Age & Diagnosis & Baseline VEDs/h & Runs ( $>3$ VEDs)/d \\
\hline $1^{*}$ & 61 & CAD & 886 & 3 \\
\hline $2^{*}$ & 48 & PED & 179 & 4 \\
\hline 3 & 71 & PED & 199 & 3 \\
\hline 4 & 36 & Cardiomyopathy & 817 & 26 \\
\hline 5 & 59 & CAD & 351 & 632 \\
\hline 6 & 62 & Mild COPD, HTN & 161 & 9 \\
\hline $7^{*}$ & 64 & CAD, HTN & 243 & 7 \\
\hline 8 & 35 & $\begin{array}{l}\text { Cardiomyopathy, } \\
\text { MV prolapse }\end{array}$ & 2438 & 4 \\
\hline $9^{*}$ & 47 & $\begin{array}{l}\text { Cardiomyopathy, } \\
\text { MV prolapse }\end{array}$ & 183 & 2 \\
\hline 10 & 50 & CAD & 537 & 2 \\
\hline
\end{tabular}

VEDs, ventricular ectopic depolarizations; CAD, coronary artery disease; PED, primary electrical disease; $C O P D$, chronic obstructive pulmonary disease; HTN, hypertension; MV, mitral valve. * Patients whose arrhythmia was refractory to prior treatment with beta-adrenergic receptor blockers.

$320 \mathrm{mg}$ orally every $6 \mathrm{~h}$ for this effect with elimination of nonsustained ventricular tachycardia in one patient and persistence of rare, three-beat episodes in the other. Two patients had no evidence of arrhythmia suppression despite treatment with the maximal dosage of $d$-propranolol.

Ventricular arrhythmia suppression and degree of betaadrenergic receptor blockade, expressed as reduction in peak exercise heart rate from baseline, are shown in Fig. 2 for the patients who responded to $d$-propranolol and subsequently received $d l$-propranolol. These data include patients with ei-

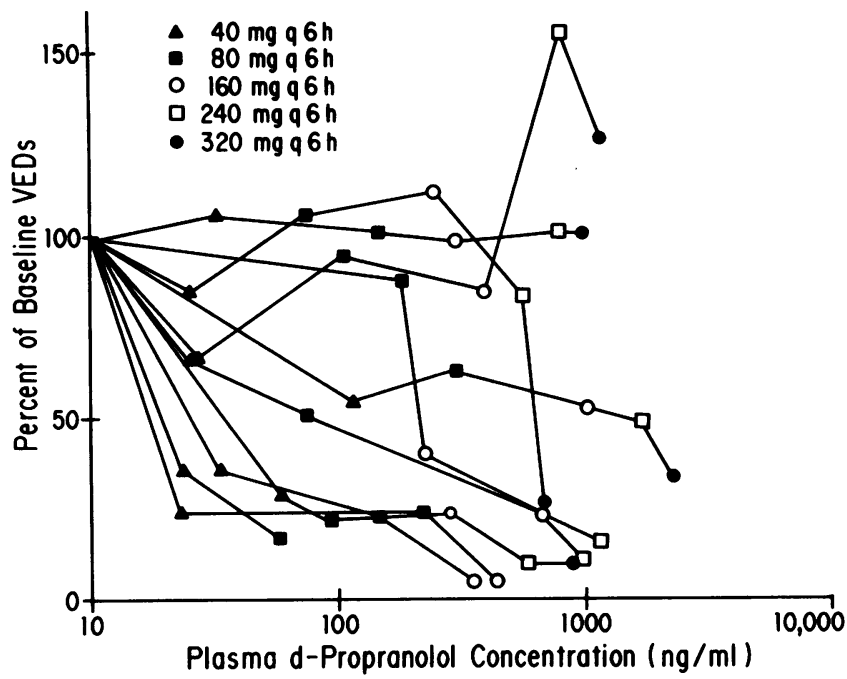

Figure 1. The plasma concentration-response relationship for suppression of VEDs is shown for all patients receiving $d$-propranolol. Plasma propranolol concentration is displayed on a logarithmic scale, while ventricular arrhythmia suppression is expressed as the percent of VEDs recorded at baseline. The dosage of $d$-propranolol being taken at the time of each plasma concentration measurement is shown using the filled and unfilled symbols as displayed on the figure.

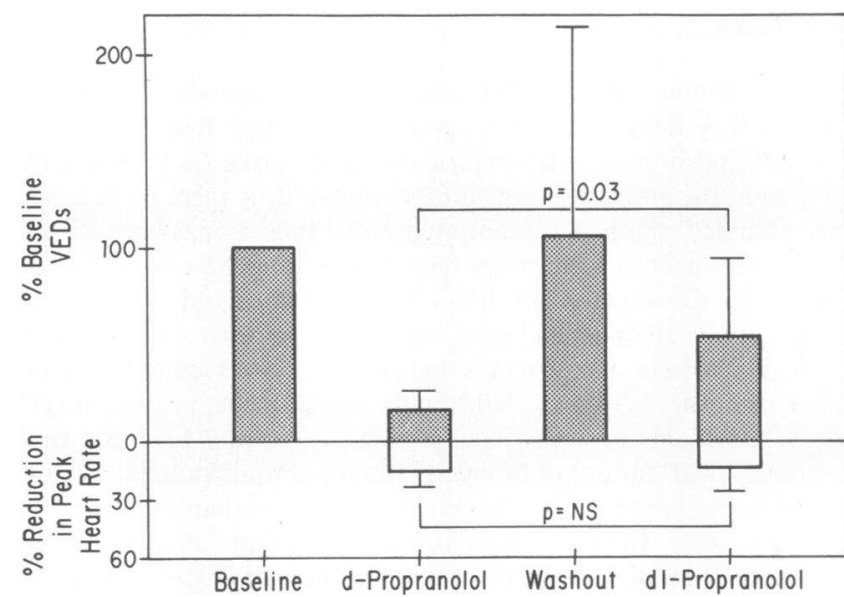

Figure 2. For patients responding to $d$-propranolol and subsequently receiving therapy with $d l$-propranolol, suppression of VEDs and associated reduction in peak heart rate at exercise testing are shown during $d$-propranolol therapy, after $d$-propranolol withdrawal, and during $d l$-propranolol therapy. Percent of baseline VEDs is illustrated by the shaded bars while percent reduction in peak exercise heart rate is represented by the unfilled bars.

ther a partial or excellent antiarrhythmic response. The degree of reduction in exercise heart rate with $d l$-propranolol $(15 \pm 7 \%)$ was similar to that seen with $d$-propranolol (14 $\pm 7 \%)$. However, antiarrhythmic efficacy of $d$-propranolol $(84 \pm 10 \%$ VED suppression) was greater than the efficacy of $d l$-propranolol (46 $\pm 40 \%$ VED suppression).

For each patient responding to $d$-propranolol, the relationship between VED suppression and reduction in exercise heart rate while receiving $d$ - (filled symbols) and $d l$ - (unfilled symbols) propranolol is shown in Fig. 3. Two patients had no reduction in exercise heart rate at the time of arrhythmia sup-

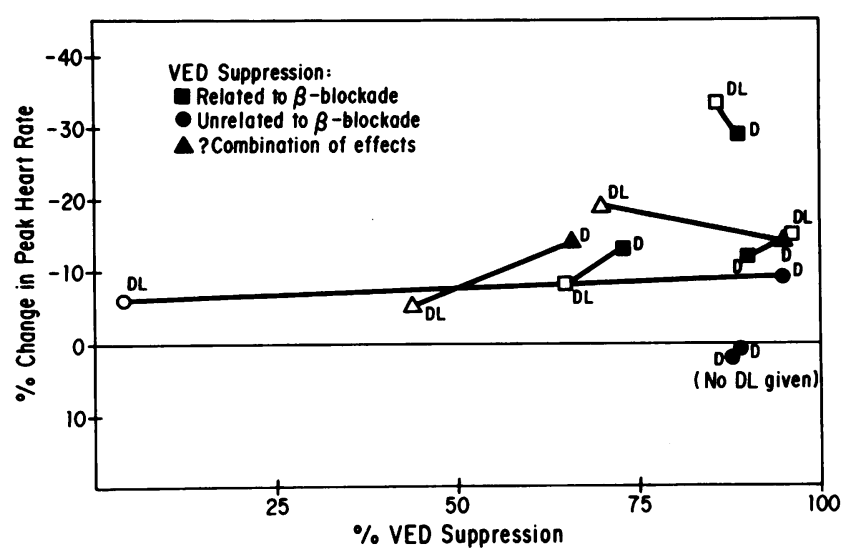

Figure 3. For each patient responding to $d$-propranolol, degree of response (percent suppression of VEDs) is shown concomitantly with percent change in peak exercise heart rate when taking $d$-propranolol (filled symbols) and dl-propranolol (unfilled symbols). Patients represented by circular symbols demonstrated ventricular arrhythmia suppression that could not be attributed to beta-adrenergic receptor blockade, while patients denoted by square symbols demonstrated antiarrhythmic effect that correlated with evidence of beta-adrenergic receptor blockade. Patients represented by triangular symbols were felt to have a combination of these two effects. (See text for further description.) 
pression with $d$-propranolol and hence no $d l$-propranolol was administered. For an additional patient, VED suppression fell from 95 to $4 \%$ during treatment with $d l$-propranolol despite a similar degree of beta-adrenergic receptor blockade. In these three patients (circular symbols), ventricular arrhythmia suppression was therefore attributed to properties other than beta-adrenergic receptor blockade. Moreover, each of these patients also had failed to demonstrate evidence of arrhythmia suppression during therapy with a beta-adrenergic receptor blocker before the study. Of the remaining five patients, three (square symbols) had little change in VED suppression during therapy with $d l$-propranolol as compared with $d$-propranolol, indicating that arrhythmia suppression was therefore likely related to beta-adrenergic receptor blockade. In the final two patients, therapy with $d l$-propranolol was associated with a partial reduction in VED frequency, but less than that seen with $d$-propranolol. In these patients (triangular symbols), arrhythmia suppression probably represented a combination of beta and non-beta receptor mediated effects. Peak heart rate at exercise testing and the dose of $\mathrm{dl}$-propranolol administered to each patient are displayed in Table II.

Electrocardiographic changes. During therapy with $d$-propranolol, no significant changes occurred in either the QRS interval $(95 \pm 17$ to $98 \pm 11 \mathrm{~ms})$ or the QT interval $(384 \pm 24$ to $400 \pm 20 \mathrm{~ms}$ ). Plasma propranolol concentration-response data for changes in the PR and QTc intervals are illustrated in Fig. 4. For the entire group, the PR interval (top panel) increased significantly with $d$-propranolol treatment $(154 \pm 17$ to $164 \pm 18$ $\mathrm{ms})$, while a reduction was seen in the QTc interval (421 \pm 32 to $404 \pm 29 \mathrm{~ms}$ ) that was also statistically significant (bottom panel). Of note despite a reduction in the PR interval, the two patients who were nonresponders developed a significant degree of beta-adrenergic receptor blockade when taking $d$-propranolol with reductions in peak exercise heart rate of $11 \%$ and $15 \%$ as compared with baseline.

Blood pressure and heart rate. No significant changes were found in systolic blood pressure, diastolic blood pressure, or mean blood pressure during therapy with $d$-propranolol. However, resting heart rate did fall significantly from a baseline value of $66 \pm 8 \mathrm{bpm}$ to $56 \pm 6 \mathrm{bpm}$ during treatment.

Pharmacokinetic analysis. Table III displays the results of the pharmacokinetic analyses. In patients with either a partial or excellent response to $d$-propranolol therapy, the mean effective dose was $920 \pm 360 \mathrm{mg} / \mathrm{d}$ with an associated mean

Table II. Exercise Testing during d-and dl-Propranolol Therapy

\begin{tabular}{ccccc}
\hline & \multicolumn{3}{c}{ Peak exercise heart rate (beats/minute) } & \\
\cline { 2 - 4 } Patient & Baseline & $d$-Propranolol & $d l$-Propranolol & dl-Propranolol dosage \\
\hline 1 & 129 & 118 & 121 & $5 \mathrm{mg} \mathrm{q} \mathrm{6} \mathrm{h}$ \\
2 & 124 & 127 & - & - \\
3 & 150 & 107 & 100 & $20 \mathrm{mg} \mathrm{q} \mathrm{6} \mathrm{h}$ \\
4 & 158 & 138 & 145 & $10 \mathrm{mg} \mathrm{q} \mathrm{6} \mathrm{h}$ \\
5 & 173 & 148 & 140 & $10 \mathrm{mg} \mathrm{q} \mathrm{6} \mathrm{h}$ \\
6 & 141 & 125 & - & - \\
7 & 141 & 121 & 134 & $10 \mathrm{mg} \mathrm{q} \mathrm{6} \mathrm{h}$ \\
8 & 163 & 138 & - & - \\
9 & 142 & 143 & - & - \\
10 & 158 & 139 & 133 & $10 \mathrm{mg} \mathrm{q} \mathrm{6} \mathrm{h}$ \\
& & & & \\
\hline
\end{tabular}

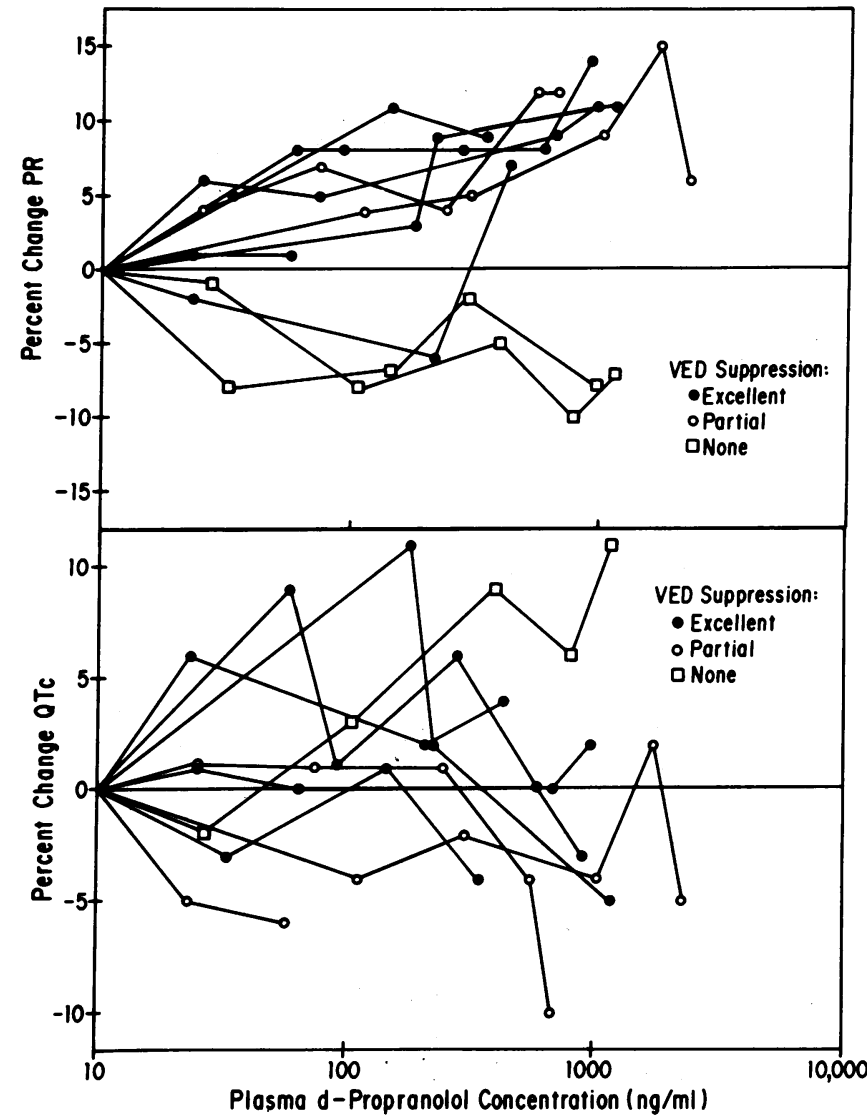

Figure 4. The plasma concentration-response relationship for changes in the PR (top panel) and QTc. (lower panel) intervals are shown for each patient receiving $d$-propranolol. Plasma propranolol concentration is displayed on a logarithmic scale while changes in ECG parameters are expressed as percent change from baseline values. Data from patients having an excellent antiarrhythmic response are represented by filled circles while patients with a partial response are shown by unfilled circles and nonresponders are represented by unfilled squares.

trough plasma concentration of $858 \pm 681 \mathrm{ng} / \mathrm{ml}$. The range of values for AUC, clearance, and elimination half-life are shown for each patient.

Adverse effects. Four patients experienced side effects, which included fatigue and drowsiness, during dose titration. In each case, these adverse effects were felt by the patients to be mild to moderate in severity and did not limit dose escalation. The total daily dosages at which side effects were experienced were $640 \mathrm{mg}$ (1), $960 \mathrm{mg}$ (1), and 1,280 (2).

Beta-adrenergic receptor blocking potency of the d-propranolol formulation. Six male normal volunteers, ages 21-35 $y$, participated in this phase of the study. The IDR vs. plasma propranolol concentration for the group when taking $d l$-propranolol and $d$-propranolol is shown in Fig. 5. Using linear regression analysis of the relationship IDR vs. log (plasma $d l$ propranolol concentration) for each subject, the ratio of the $d$-propranolol to $d l$-propranolol plasma concentrations which produced similar degrees of beta-blockade (equivalent IDRs) was individually calculated. For the group, the average value of this ratio was $155.1 \pm 106.2$. Thus, $d l$-propranolol was over 100 times more potent than $d$-propranolol in producing betaadrenergic receptor blockade. 
Table III. d-Propranolol Pharmacokinetics

\begin{tabular}{cccrrc}
\hline Patient & $\begin{array}{c}\text { Effective } \\
\text { dose }\end{array}$ & $\begin{array}{c}\text { Trough } \\
\text { effective } \\
\text { plasma } \\
\text { concentration }\end{array}$ & AUC & Clearance & $\begin{array}{c}\text { Elimination } \\
\text { half-life }\end{array}$ \\
\hline & $m g / d$ & $n g / m l$ & $n g h / m l$ & $m l / m i n$ & $h$ \\
$1^{*}$ & 640 & 430 & 2,921 & 913 & 6.3 \\
$2^{*}$ & 320 & 60 & 4,113 & 1,297 & 4.3 \\
$3^{*}$ & 960 & 970 & 7,134 & 561 & 8.0 \\
$4^{\ddagger}$ & 1,280 & 680 & 4,066 & 1,312 & 4.8 \\
$5^{*}$ & 640 & 350 & 2,078 & 1,283 & 6.6 \\
6 & - & - & 7,629 & 699 & 6.7 \\
$7^{\ddagger}$ & 1,280 & 2,280 & 13,133 & 406 & 6.7 \\
8 & - & - & 5,599 & 953 & 7.0 \\
$9^{*}$ & 960 & 1,180 & 7,829 & 511 & 4.3 \\
$10^{*}$ & 1,280 & 910 & 6,290 & 954 & 7.5 \\
Mean & 920 & 858 & 6,079 & 889 & 6.3 \\
Standard & & & & & \\
deviation & \pm 360 & \pm 681 & $\pm 3,171$ & \pm 338 & \pm 1.5 \\
\hline
\end{tabular}

AUC, area under the plasma concentration-time curve.

* Patients with an excellent antiarrhythmic response.

‡ Patients with a partial antiarrhythmic response.

In the arrhythmia suppression trial, plasma concentrations of $d l$-propranolol were also obtained for two patients whose arrhythmias were suppressed by $d$-propranolol and who subsequently received the racemic preparation. In dosages that produced equal degrees of beta-adrenergic receptor blockade, the ratio of $d$-propranolol to $d l$-propranolol plasma concentrations exceeded 100 in both patients (120 and 432).

\section{Discussion}

The results of our study demonstrate that $d$-propranolol is effective in suppressing chronic, stable ventricular arrhythmias in man. In some patients, antiarrhythmic effect was probably related to beta-adrenergic receptor blockade, while in others, arrhythmia suppression developed in the absence of evidence for beta-adrenergic antagonism. In this latter group of patients, antiarrhythmic response was either not associated with a reduction in peak exercise heart rate, or diminished when $\mathrm{dl}$ propranolol therapy was substituted to produce a similar degree of beta-blockade. In the remaining patients, ventricular arrhythmia suppression appeared to represent a combination of beta- and non-beta-mediated effects. However, conclusions

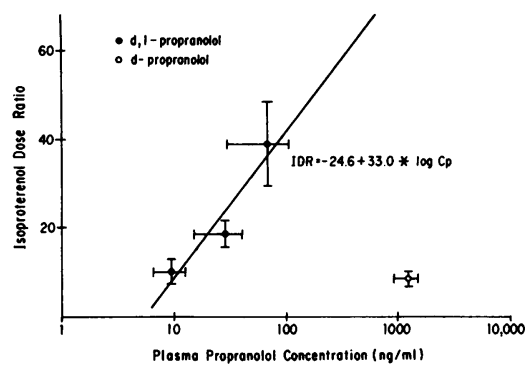

Figure 5. IDR data for subjects receiving sequential doses of $d l$-propranolol and a single dose of $d$-propranolol are plotted against plasma propranolol concentration expressed on a logarithmic scale. Data points during $\mathrm{dl}$ propranolol therapy are

illustrated by filled circles while data during $d$-propranolol therapy are shown with unfilled circles. regarding mechanism of arrhythmia suppression in this group are at best somewhat speculative, as the differences observed during $d$ - and $d l$-propranolol therapy are small and perhaps influenced by spontaneous day-to-day variability in VED frequency. For patients in whom arrhythmia suppression appeared related to beta-adrenergic receptor blockade, the contribution of non-beta-mediated properties cannot be ruled out. However, it is likely that beta blockade played an important role in the pharmacologic effects of $d$-propranolol in these patients, given the low dosages of $d l$-propranolol that reproduced such effects. At the time of baseline exercise testing, there was no obvious evidence of adrenergically mediated arrhythmias in any of the patients studied. For this reason, it is possible the incidence of arrhythmia suppression due to nonbeta-mediated effects was higher in our patient group than expected in the general population of patients with chronic ventricular arrhythmias.

Considerable controversy exists regarding the mechanism(s) by which propranolol suppresses arrhythmias (28), and our report describes for the first time antiarrhythmic effects that are unrelated to beta blockade. A review of previous investigations in this area suggests that the additional pharmacologic property involved (besides beta blockade) may be local anesthetic or sodium channel blocking activity. Vaughan Williams and co-workers (7) first noted that racemic propranolol produced evidence of sodium channel blockade with a reduction in the maximum rate of rise of the phase 0 upstroke slope $\left(\dot{\mathrm{V}}_{\max }\right)$ of the cardiac action potential in rabbit atrium and shortening of action potential duration at a single bath concentration of $3,000 \mathrm{ng} / \mathrm{ml}$. In an early concentration-response study, a propranolol bath concentration of $3,000 \mathrm{ng} / \mathrm{ml}$ was necessary to cause a reduction in $\dot{\mathrm{V}}_{\max }$ in canine Purkinje fibers and ventricular muscle using a brief period of drug exposure (15 $\mathrm{min}$ ) (16). More recent data using the pharmacologic probe tetrodotoxin suggest that sodium channel blockade in vitro reduces action potential duration at concentrations lower than those depressing $\dot{\mathrm{V}}_{\max }$ (29). With this information, Pruett and co-workers concluded from a series of experiments that electrophysiologic changes that could represent local anesthetic activity were present at lower concentrations of $d$ - and $d l$-propranolol $(17,18)$ than those used previously. They found that $d$ - and $d l$-propranolol shortened action potential duration in canine Purkinje fibers with similar potency at bath concentrations as low as $100 \mathrm{ng} / \mathrm{ml}$, and that progressive changes occurred up to $120 \mathrm{~min}$ of exposure. Antiarrhythmic activity actually correlated better with tissue propranolol content than with bath concentration, and when this was taken into account, the minimum plasma propranolol concentration expected to produce an electrophysiologic effect in patients was determined to be $150 \mathrm{ng} / \mathrm{ml}$. Such a value is well within the range of plasma concentrations observed during routine clinical therapy with propranolol.

Before this investigation, several studies were performed to determine if propranolol could produce electrophysiologic effects that were unrelated to beta-blockade, both in intact animal models and in humans. In two groups of dogs, high-dose $d$-propranolol prolonged His-Purkinje conduction time and increased the ratio of ventricular effective refractory period (VERP) to monophasic action potential duration (APD) when compared with a dose of $d l$-propranolol that produced a similar degree of beta-blockade (30). These findings were confirmed in a subsequent study in which a single group of dogs 
received infusions of both drugs (31). In a cohort of patients undergoing electrophysiologic study, Duff and colleagues found that infusion of high-dose racemic propranolol caused a reduction in the QTc interval and monophasic APD with an increase in the ratio of VERP to monophasic APD as compared to a low-dose infusion which nonetheless produced significant beta-blockade (19). This again suggested the participation of additional pharmacologic properties in producing such changes. To eliminate the possibility that these effects were due to progressive beta-blockade at the higher dosage, a subsequent investigation was performed by the same authors in which patients received low-dose $d l$-propranolol and high-dose $d$-propranolol infusions, matched to produce equal degrees of beta-blockade (20). Treatment with $d$-propranolol caused a significant reduction in monophasic APD and QT interval, with an increase in the ratio of VERP to monophasic APD. Such changes were not present during therapy with $d l$-propranolol. These results demonstrated conclusively that electrophysiologic effects could be seen in man with $d$-propranolol therapy that could not be attributed to beta-adrenergic receptor blockade. However, the role of these effects in arrhythmia suppression was not known.

Our results regarding the antiarrhythmic effects of $d$-propranolol are consistent with previous reports by other investigators. This property was initially described by Lucchesi and colleagues (32) in a canine model of ouabain-induced ventricular arrhythmias. In the isolated rat heart, $d$-propranolol was as effective as racemic beta-adrenergic antagonists in preventing arrhythmias after coronary occlusion (33) and subsequent reperfusion (34). In small groups of patients, there have been anecdotal reports that $d$-propranolol can suppress premature atrial and ventricular depolarizations $(35,36)$. However, none of these investigations explored the mechanism of its antiarrhythmic actions.

In the present study, racemic propranolol was found to be over 100 times more potent $d$-propranolol in producing betaadrenergic receptor blockade. These findings are consistent with the early results of Barrett and Cullum (23) in anesthetized rats. In patients in the present study whose antiarrhythmic response was felt to be unrelated to beta-blockade, predose effective plasma $d$-propranolol concentrations were 60,430 , and $1,180 \mathrm{ng} / \mathrm{ml}$. Corresponding values for $d l$-propranolol plasma concentrations would be exceedingly low $(<12 \mathrm{ng} / \mathrm{ml})$ and unlikely to result in substantial beta-blockade. Moreover, the arrhythmias of these three patients were previously found to be refractory to beta-blocker therapy, lending additional support to the argument that their response to $d$-propranolol was not due to beta-blockade.

In assessing beta-blockade in our patient population, we chose to use peak heart rate during exercise rather than isoproterenol sensitivity as employed in the normal volunteers. All of the patients participating had nonsustained ventricular tachycardia at baseline, and it is known that isoproterenol administration can facilitate induction of sustained ventricular tachycardia during programmed ventricular stimulation in patients with a history of only nonsustained ventricular tachycardia $(37,38)$. In addition, plasma propranolol levels correlate well with reduction in exercise heart rate (39), especially in individuals undergoing repeated evaluations (40). For these reasons, we felt that exercise testing was a reliable, safe method to use in this patient population.

In general, therapy with $d$-propranolol was associated with a reduction in the QTc interval, although this was not a prerequisite for successful therapy as two of the six patients with an excellent antiarrhythmic response developed QTc prolongation from baseline values. This is consistent with previous data in humans (noted above) showing a reduction in the QTc interval and monophasic APD during treatment with $d$ - and $d l$-propranolol $(19,20)$, suggesting that ventricular repolarization is shortened. However, it should be recognized that measurement of the QT interval during normal sinus rhythm as performed in this study probably does not correct sufficiently for variation due to either heart rate or underlying cholinergic tone (41). It has also been shown that use of Bazett's formula in calculating QTc to correct for heart rate may be more inaccurate after pharmacologic interventions (42). During $d$-propranolol therapy, the PR interval lengthened for the group as a whole. This is probably due to contribution of beta-adrenergic receptor blockade in some patients, as prolongation of atrioventricular nodal conduction in this situation is well described (43).

In summary, $d$-propranolol is an effective antiarrhythmic agent in patients with chronic, frequent ventricular ectopic depolarizations and nonsustained ventricular tachycardia. In some patients, arrhythmia suppression could not be attributed to beta-adrenergic receptor blockade based on results of exercise testing and determination of plasma propranolol concentrations. Overall, shortening of ventricular repolarization was seen during therapy consistent with the concept that in some patients, local anesthetic activity may play a role in these nonbeta-mediated effects. As propranolol has been shown to reduce the incidence of sudden death following acute myocardial infarction and because many patients at highest risk (those with poor left ventricular function) may not tolerate betaadrenergic receptor blockade, $d$-propranolol merits further investigation as an antiarrhythmic agent.

\section{Acknowledgments}

The assistance of Patricia Chaffin, R.N., in the conduct of this study and Kimberley Webb and Rosemary Hoffman in the preparation of the manuscript is greatly appreciated.

This study was supported by grants from the U. S. Public Health Service (GM-07569, HL-26782) and the General Clinical Research Center (RR-0095). Dr. Murray is a Charles E. Culpepper Foundation Medical Scholar.

\section{References}

1. Beta-blocker Heart Attack Trial Research Group. 1982. A randomized trial of propranolol in patients with acute myocardial infarction: I. Mortality results. JAMA (J. Am. Med. Assoc.) 247:1707-1714.

2. Norwegian Multicenter Study Group. 1981. Timolol-induced reduction in mortality in reinfarction in patients surviving acute myocardial infarction. N. Engl. J. Med. 304:801-807.

3. Hjalmarson, A., D. Elmfeldt, J. Herlitz, S. Holmberg, I. Malek, G. Nyberg, L. Ryden, K. Swedberg, A. Vedin, F. Waagstein, A. Waldenstrom, J. Waldenstrom, H. Wedel, L. Wilhelmsen, and C. Wilhelmsson. 1981. Effect on mortality of metoprolol in acute myocardial infarction: a double-blind randomised trial. Lancet. ii:823-827.

4. Julian, D. G., F. S. Jackson, R. J. Prescott, and P. Szekely. 1982. Controlled trial of sotalol for one year after myocardial infarction. Lancet. i:1142-1147.

5. Lichstein, E., J. Morganroth, R. Harrist, and E. Hubble. 1983. Effect of propranolol on ventricular arrhythmia: The Beta-blocker Heart Attack Trial experience. Circulation. 67(Suppl. I):I5-I10. 
6. Furberg, C. D., C. M. Hawkins, and E. Lichstein for the Betablocker Heart Attack Trial Study group. 1984. Effect of propranolol in postinfarction patients with mechanical or electrical complications. Circulation. 69:761-765.

7. Morales-Aguilera, A., and E. M. Vaughan Williams. 1965. The effects on cardiac muscle of beta-receptor antagonists in relation to their activity as local anesthetics. Br. J. Pharmacol. 24:332-338.

8. Winkle, R. A., A. H. Gradman, and J. W. Fitzgerald. 1978 Antiarrhythmic drug effect assessed from ventricular arrhythmia reduction in the ambulatory electrocardiogram and treadmill test: Comparison of propranolol, procainamide and quinidine. Am. J. Cardiol. 42:473-480.

9. Gianelly, R., J. R. Griffin, and D. C. Harrison. 1967. Propranolol in the treatment and prevention of cardiac arrhythmias. Ann. Intern. Med. 66:667-676.

10. Wellens, H. J. J., F. W. H. M. Bar, K. I. Lie, D. R. Duren, and H. J. Dohmen. 1977. Effect of procainamide, propranolol and verapamil on mechanism of tachycardia in patients with chronic recurrent ventricular tachycardia. Am. J. Cardiol. 40:579-585.

11. Bigger, J. T., and J. Coromilas. 1984. How do beta-blockers protect after myocardial infarction? Ann. Intern. Med. 101:256-258.

12. Zipes, D. L. 1984. Management of cardiac arrhythmias: Pharmacological, electrical and surgical techniques. In Heart Disease: A Textbook of Cardiovascular Medicine. E. Braunwald, editor. W. B. Saunders Co., Philadelphia. 648-682.

13. Woosley, R. L., D. Kornhauser, R. Smith, S. Reele, S. B. Higgins, A. S. Nies, D. G. Shand, and J. A. Oates. 1979. Suppression of chronic ventricular arrhythmias with propranolol. Circulation. 60:819-827.

14. Coltart, D. J., and D. G. Shand. 1970. Plasma propranolol levels in the quantitative assessment of beta-adrenergic blockade in man. Br. Med. J. 3:731-734.

15. Chidsey, C., M. Pine, L. Favrot, S. Smith, G. Leonetti, P. Morselli, and A. Zanchetti. 1976. The use of drug concentration measurements in studies of the therapeutic response to propranolol. Postgrad. Med. J. 52(Suppl. 4):26-32.

16. Davis, L. D., and J. V. Temte. 1968. Effects of propranolol on the transmembrane potentials of ventricular muscle and Purkinje fibers of the dog. Circ. Res. 22:661-667.

17. Pruett, J. K., T. Walle, and E. E. Bagwell. 1977. Association of in vivo and in vitro propranolol levels in canine Purkinje fibers with antiarrhythmic effects. J. Pharmacol. Exp. Ther. 202:45-54.

18. Pruett, J. K., T. Walle, and U. K. Walle. 1980. Propranolol effects on membrane repolarization time in isolated canine Purkinje fibers: Threshold tissue content and the influence of exposure time. $J$. Pharmacol. Exp. Ther. 215:539-543.

19. Duff, H. J,, D. M. Roden, L. Brorson, A. J. J. Wood, A. K. Dawson, R. K. Primm, J. A. Oates, R. F. Smith, and R. L. Woosley. 1983. Electrophysiologic actions of high plasma concentrations of propranolol in human subjects. J. Am. Coll. Cardiol. 2:1134-1140.

20. Duff, H. J., A. J. J. Wood, A. K. Dawson, D. M. Roden, R. K. Primm, R. F. Smith, and R. L. Woosley. 1982. d-Propranolol: Nonadrenergically mediated electrophysiologic actions in man. Circulation. 66(Suppl. II):II-372. (Abstr.)

21. Howe, R., and R. G. Shanks. 1966. Optical isomers of propranolol. Nature (Lond.). 210:1336-1338.

22. Alexander, R. W., L. T. Williams, and R. J. Lefkowitz. 1975. Identification of cardiac beta-adrenergic receptors by $(-)\left[{ }^{3} \mathrm{H}\right]$ alprenolol binding. Proc. Natl. Acad. Sci. USA. 72:1564-1568.

23. Barrett, A. M., and V. A. Cullum. 1968. The biological properties of the optical isomers of propranolol and their effects on cardiac arrhythmias. Br. J. Pharmacol. 34:43-55.

24. Bruce, R. A., J. R. Blackmon, J. W. Jones, and G. Strait. 1963. Exercise testing in adult normal subjects and cardiac patients. Pediatrics. 32:742-756.

25. Higgins, S.B., R. L. Woosley, C. B. Herrin, J. L. Compton, and T. R. Harris. 1978. A mini-computer-based system for quantification of ventricular arrhythmias. In Computers in Cardiology. 5th Conference. Ripley, K. L., and Ostrow, H. G., editors. IEEE Computer Society, Long Beach, CA. 355-358.

26. Koshakji, R. P., and A. J. J. Wood. 1986. A modified, sensitive liquid chromatographic method for measurement of propranolol with fluorescence detection. J. Pharm. Sci. 75:87-89.

27. Cleaveland, C. R., E. R. Rangno, and D. G. Shand. 1972. A standardized isoproterenol sensitivity test. Arch. Intern. Med. 130:4752 .

28. Nies, A. S., and R. L. Woosley. 1978. The non-beta-adrenergic blocking actions of propranolol. In Beta-adrenergic Blockade: A New Era in Cardiovascular Medicine. E. Braunwald, editor. Excerpta Medica/Amsterdam. 113-130.

29. Coraboeuf, E., E. Deroubaix, and A. Coulombe. 1979. Effect of tetrodotoxin on action potentials of the conducting system in the dog heart. Am. J. Physiol. 236:H561-H567.

30. Brorson, L., S. Reele, W. Dupont, R. Woosley, D. Shand, and R. Smith. 1981. Effects of concentration and steric configuration of propranolol on conduction and ventricular repolarization in the dog. J. Cardiovasc. Pharmacol. 3:692-703. “

31. Dawson, A. K., S. B. Reele, A. J. J. Wood, H. J. Duff, R. L. Woosley, and R. F. Smith. 1984. Electrophysiologic effects of highdose propranolol in dogs: Evidence in vivo for effects not mediated by the beta adrenoceptor. J. Pharmacol. Exp. Ther. 229:91-97.

32. Lucchesi, B. R., L. S. Whitsitt, and J. L. Stickney. 1967. Antiarrhythmic effects of beta adrenergic blocking agents. Ann. NY Acad. Sci. 139:940-951.

33. Lubbe, W. F., C. A. Muller, M. Worthington, E. L. McFadyen, and L. H. Opie. 1981. Influence of propranolol isomers and atenolol on myocardial cyclic AMP, high energy phosphates and vulnerability to fibrillation after coronary artery. ligation in the isolated rat heart. Cardiovasc. Res. 15:690-699.

34. Rochette, L., J.-P. Didier, D. Moreau, J. Bralet, and L. H. Opie. 1984. Role of beta-adrenoceptor antagonism in the prevention of reperfusion ventricular arrhythmias: Effects of acebutolol, atenolol, and d-propranolol on isolated working rat hearts subject to myocardial ischemia and reperfusion. Am. Heart J. 107:1132-1141.

35. Howitt, G., M. Husaini, D. J. Rowlands, W. F. W. E. Logan, R. G. Shanks, and M. G. Evans. 1968. The effect of the dextro isomer of propranolol on sinus rate and cardiac arrhythmias. Am. Heart J. 76:736-745.

36. Smith, E., D. Bennet, and E. Sowton. 1971. A comparative study of dextro-alprenolol, dextro-propranolol and practolol in the treatment of ventricular ectopic beats. Guys Hosp. Rep. 120:9-15.

37. Mason, J. W., and R. A. Winkle. 1978. Electrode-catheter arrhythmia induction in the selection and assessment of antiarrhythmic drug therapy for recurrent ventricular tachycardia. Circulation. 58:971-985.

38. Reddy, C. P., and L. S. Gettes. 1979. Use of isoproterenol as an aid to electric induction of chronic recurrent ventricular tachycardia. Am. J. Cardiol. 44:705-713.

39. Hager, W. D., H. J. Pieniaszek, D. Perrier, M. Mayersohn, and V. Goldberger. 1981. Assessment of beta blockade with propranolol. Clin. Pharmacol. Ther. 30:283-290.

40. Tawara, K., E. Steiner, and C. von Bahr. 1987. The effect of propranolol on exercise induced tachycardia is determined by plasma concentration and the density of adrenergic receptors on leukocytes. Eur. J. Clin. Pharmacol. 31:667-672.

41. Ahnve, S., and H. Vallin. 1982. Influence of heart rate and inhibition of autonomic tone on the QT interval. Circulation. 65:435439.

42. Browne, K. F., D. P. Zipes, J. J. Heger, and E. N. Prystowsky. 1982. Influence of the autonomic nervous system on the Q-T interval in man. Am. J. Cardiol. 50:1099-1103.

43. Berkowitz, W. D., A. L. Wit, S. H. Lau, C. Steiner, and A. N. Damato. 1969. The effects of propranolol on cardiac conduction. Circulation. 40:855-862. 